\title{
Palabras de gratitud
}

Queremos compartir con nuestros colaboradores y púbico en general, que la continuidad de la edición impresa de la revista Cultura de Paz, la debemos a la expresión de solidaridad de siempre, del Profesor Federico Mayor Zaragoza, Presidente de la Fundación Cultura de Paz.

Él, al ser de su conocimiento los daños ocasionados a nuestra Universidad, a partir de la crisis de abril del 2018, que afectó drásticamente la posibilidad de continuar con su edición, se comprometió a patrocinar

los próximos cuatro números, mientras la Universidad recupera su normalidad. Agradecemos vivamente este gesto fraternal, coherente con los valores vivos y cotidianos de la cultura de paz.

\section{Hacia una Cultura de Reconciliación}

Por Denis Torres ${ }^{1}$

La reconciliación la entendemos como procesos profundos de encuentro y conocimiento del Otro, de sus intereses, del conocimiento de sus percepciones y tiene como base la justicia y la verdad que resarce el daño que originó la ruptura. La reconciliación conlleva tolerancia que es el reconocimiento y aprecio de la diversidad y que lleva, incluso, a reconocernos a nosotros mismos en el Otro y a la posibilidad de una nueva unidad en la diversidad.

Reconciliación es una palabra que transcribe "la acción de restituir relaciones quebrantadas", significa en un sentido amplio, restituir la unidad perdida de la humanidad, ya sea por causa de nuestro egoísmo, nuestra ambición de poder y el afán de dominio sobre la naturaleza; así mismo por causa del concepto de racionalidad única que se vive. Todas estas actitudes y pasiones han conducido a la humanidad a una ruptura consigo misma, y a constituir dicotomías irreconciliables que han persistido a través de las épocas, derivando en la guerra total entre diferentes órdenes de la sociedad humana, la exclusión y la catástrofe ecológica.

Como dice nuestro pensador Erwin Silva $(2008)^{2}$, nos recuerda, que en la base de todas las religiones existe un sustrato de reconciliación, justicia, amor y perdón:

Nos recuerda queen el Islam el Tawid es unificación de todo lo creado, que el hinduismo y budismo con el Dharma incorpora cohesión y con Ahimsa la no violencia y tolerancia. También anota que el judaísmo con la doctrina del Tikku Olam convoca a enmendar al mundo a través de la Alianza con el pueblo escogido y que la Katallagé cristiana con sus componentes de perdón, justicia y cambio complementan la visión de la reconciliación desde

1 Director del Instituto Martin Luther King (UPOLI). Correo: imlk@upoli.edu.ni. ORCID: https://orcid.org/0000-0002-3437-476X

2 Mayor, F., Kobia S. y Castro, E. (2008). Historia y Reconciliación. Managua: Nos-Otros, Instituto Martin Luther King (UPOLI). 
las religiones y otros sistemas culturales ante la variada problemática del mundo.

La Reconciliación también nos habla de concilio, de volver a reunirse, adquiriendo una poderosa razón de existencia en nuestro mundo de hoy, que ha generado la división de todo; de la psiquis, del mundo natural y de los seres, en una terrible esquizofrenia.

Reconciliación es un encuentro en la palabra y supone dos partes que guardan una relación de dominio o conflicto con respeto a algo: riqueza, territorio, poder o verdad.

Reconciliación es un derecho y deber humano, no solo porque tenemos derecho a la verdad, a la justicia, a la reparación y a la no repetición, sino también porque es una exigencia en el contexto actual de crisis valórica y moral.

La Reconciliación comprende el reconocimiento de nuestras propias faltas, la Reconciliación es pactar la paz con la tierra como elemento y Casa de la Humanidad. La Reconciliación es una aspiración y práctica de la humanidad para garantizar estabilidad y paz duradera.

San Oscar Arnulfo Romero dice: "En las circunstancias que vivimos de polarización e instransigencia, de mucho odio a muerte y un egoísmo insoportable, ese es un ambiente verdaderamente necesitado, como nunca, de reconciliación".

San Juan Pablo II afirma: "La reconciliación se hace necesaria porque ha habido una ruptura...de la (n) cual se han derivado todas las otras formas de rupturas, en lo mas íntimo del hombre y en su entorno".

Agustín Morán dice que: "La fuerza de la reconciliación no solo procede de la memoria, la voluntad sincera de paz de los contendientes y la generocidad de todas las víctimas. Procede sobre todo,

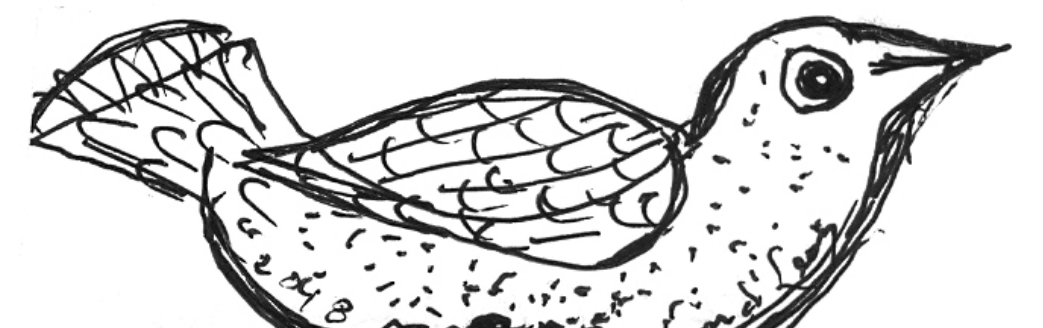




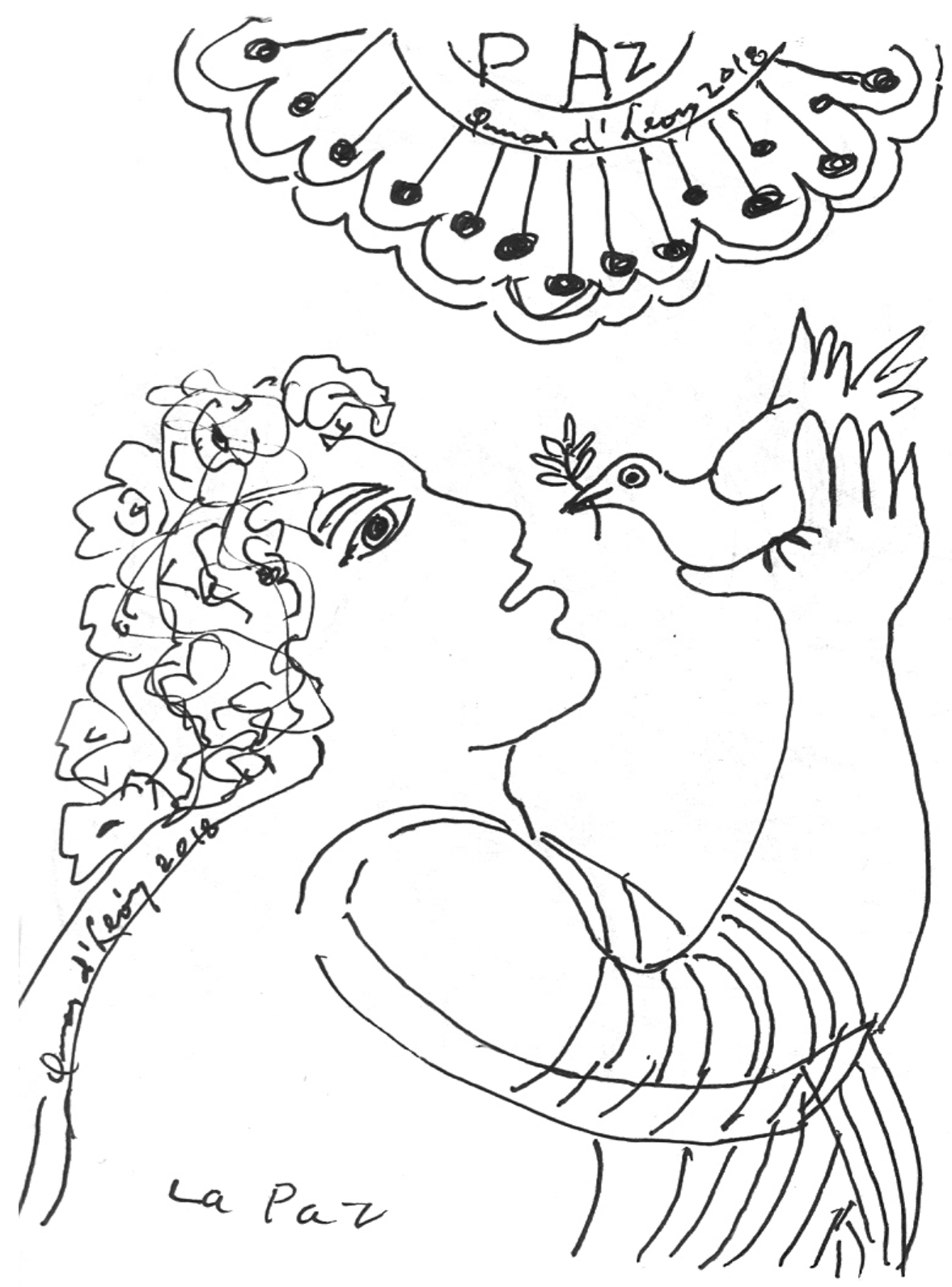

del restablecimiento de los derechos y de la justicia cuya vulneración generó el conflicto y su cadena de violencias. La reconciliación, tras el restablecimiento de la justicia, será recíproca o no será".

Emerson Pérez (2008), en la obra Historia y Reconciliación ${ }^{4}$, nos señala:

... la actual, es una realidad caracterizada por la complejidad y la adversidad, en la que nos sentimos interpelados a trabajar por conseguir juntos objetivos que no alcanzaríamos separados, para transformar y redimir a nuestros países y una humanidad atravesada por el desconcierto y el abatimiento, cuando miles de millones de seres humanos han perdido la confianza en las condiciones mundiales imperantes y ven quebrárseles día a día todas sus seguridades; cuando se vive un estado de alteración física y psíquica, cuando destruimos el entorno 
ecológico, el hábitat, con la contaminación creciente y el progreso degenerativo de una humanidad que marcha hacia su autodestrucción, aun y a pesar de sus innegables logros científico-tecnológicos, puestos al servicio de la acumulación y el poder.

Es por todo lo anterior que en la búsqueda de una utopía movilizadora de las causas y luchas humanas, nos inscribimos como UPOLI en la causa de la Reconciliación, que es sobre todo una comunión realizadora del ser; un compartir solidario ante las exclusiones, la marginación y la desigualdad de oportunidades; un reconstruir lo quebrantado, sobrela base dela verdady lajusticia, la eliminación de los desacuerdos más profundos, el enfrentamiento de diferencias desgastantes, pero con una nueva disposición interior. Es la unión de capacidades y potencialidades de actores sociales antes confrontados, para buscar alternativas de solución, salidas constructivas, nuevas propuestas económicas y sociales, operativas en la justa distribución de la riqueza, el ingreso, los salarios dignos, todo esto en pro del bien común. Es por ello también una nueva manera de ver la realidad, entenderla y resolverla para que podamos vivir en la cultura de paz.

La Reconciliación no es una visión ni una conciencia ingenua de la vida, ya que también es una ruptura radical, con ideales que están desacreditados porque perdieron su poder y credibilidad, como la libertad económica que condujo a la explotación inmisericorde, como la falsa práctica de los derechos humanos que nunca se aplicaron a la esfera económica, ni a la esfera política, social y medioambiental como los valores del individuo que llevaron al encierro en sí mismo para servir sólo a sus intereses egoístas; la cacareada democracia que no ha contribuido a transformar radicalmente la sociedad, condenándose a ser carente de creatividad y vida espiritual.

Nos inscribimos en la Reconciliación que se nutre de gratitud, humildad y misericordia, que permite una compresión más profunda de los seres humanos, que no incorpora el odio, el miedo, ni el orgullo que cansan el espíritu, sino el amor que nunca dejará de ser y que sazonando el sentido de justicia y la verdad produce la maduración para la Reconciliación.

Nos inscribimos en la Reconciliación como paradigma del Reino de Dios por excelencia, que produce el tiempo de la Gracia, de la justicia y la paz, y ese es el Dios que estaba en Cristo reconciliando consigo al mundo y nos encargó a nosotros los que creemos en Él, el Ministerio y la Palabra de la Reconciliación.

En nuestro contexto nicaragüense, es también una condición para el desarrollo en la medida en que la reconciliación permitirá unir tras un propósito común y superior a las fuerzas ahora antagonizadas y dispersas, pero creadoras en nuestra sociedad.

Nuestro país ha entrado a una fase decisiva de su historia, un proceso de diálogo y negociación que se propone llegar a acuerdos que sean base para la construcción de una paz duradera, la democracia, un estado social de derecho y el desarrollo humano sostenible.

Dadalacultura de violencia quenoscaracteriza, los contenidos de la negociación son particularmente complejos y exigen de las partes levantar la bandera de la paz como el bien más preciado de la sociedad; asumir todo el proceso negociador teniendo presente la perspectiva y sentimientos de las víctimas y la garantía para las futuras generaciones de que nuestra historia no vuelva a repetirse, sentando los fundamentos de una Cultura de Paz que de cimiento, consistencia y permanencia a los cambios políticos. Los cambios constitucionales e institucionales son importantes en sí mismos, pero la fuerza de la cultura de la violencia podría imponerse nuevamente si no van acompañados por el cambio de mentalidades de paz y democracia.

Managua, 31 de enero de 2019

Instituto Martin Luther King - UPOLI 19 de enero de 2018 